\title{
Assessment of Membrane Bioreactor in Treating Spent Sulfidic Caustic Wastewater: Effects of Organic Biomass Concentration and Solid Retention Time
}

\author{
Noor Sabrina Ahmad Mutamim ${ }^{1, *}$, Zainura Zainon Noor ${ }^{2}$ \\ ${ }^{1}$ Department of Chemical Engineering, Faculty of Chemical Engineering and Natural Resources, Universiti Malaysia \\ Pahang, LeburayaTunRazak, 26300 Gambang, Kuantan, Pahang, Malaysia. Institute of Environmental and Water \\ Resource Management (IEWRM), Water Research Alliance, UTM. Article Info: Submitted on March 20, 2017, Accepted \\ on June 20, 2017.
}

\begin{abstract}
This paper presents a study on the performance of an Aerobic Submerged u-shaped membrane bioreactor (ASMBR) in treating sulfidic spent caustic (SSC) in terms of mixed liquor suspended solid (MLSS) concentration and solid retention time (SRT). SSC wastewater is categorized as high strength wastewater and consists of high inorganic and organic matter. U-shape membrane bioreactors have a higher tendency to foul compared to other types of MBR. MLSS concentration and SRT are the major parameters when operating membrane bioreactor. In this study, COD removal recorded reduction of more than $95 \%$ for average MLSS concentration runs and $90 \%$ for SRTs runs. Meanwhile, sulfide was removed $99 \%$, and formed up to $79 \%$ of sulfate. The biofouling for MLSS concentration and SRTs were observed through TMP rate change and TMP average performance, TMP trend and SMP and EPS trends. Biocake layer and biolayer deposited on membrane surface was found influenced by biomass, the inert particulate biomass products accumulating in the reactor.
\end{abstract}

Keywords:Membrane bioreactor; Spent caustic; SRT; MLSS; Biofouling.

\section{Introduction}

Recently, industries face a lot of challenges in fulfilling wastewater discharge requirements. This is because high strength wastewater contains high concentration of toxic contaminants such as heavy metal, aromatic compounds that may lead to the reduction of their treatment ability. ${ }^{1,2}$

Sulfidic spent caustic (SSC) is known as high strength wastewater due to its high content of non-readily biodegradable elements of organic and inorganic sulfide. ${ }^{1}$ This content depends on the source ${ }^{3}$ (e.g., petroleum refineries and petrochemicals). High content of sulfide in spent caustic would lead to pipeline corrosion, toxicity to the air and bad odor to the environment besides giving rotten-egg odor. Generally, physico-chemical processes are used to treat spent caustic to reduce toxicity in some point before it can be discharged into conventional biological treatment. These processes can only remove about $70 \%$ to $90 \%$ of COD, therefore, the treated effluent still needs further treatment. Other than that, the operational cost is high apart from causing adverse environmental impacts due to the use of high temperature, pressure and chemicals ${ }^{4}$. The organic and inorganic substances in spent caustic are also only partly oxidized in the processes, hence, it needs further treatment. Spent caustic is commercially treated by applying wet air oxidation, liquid incineration or disposal by using deep-well injection. ${ }^{5}$ Most treatments are commonly followed by biological treatment because the latter treatment will remove the organic as well as inorganic pollutants.

Sulfides in spent caustic that is treated by bioreactor may be biologically and chemically oxidized into sulfate. ${ }^{6}$ Sulfides in spent caustic oxidize biologically to produce sulfate as a result of complete oxidation and sulfur under limited oxygen. These processes are shown in the reactions equations below via: ${ }^{5,7}$

$$
\begin{aligned}
& \mathrm{HS}^{-}+2 \mathrm{O}_{2} \rightarrow \mathrm{SO}_{4}{ }^{2-}+\mathrm{H}^{+} \\
& \mathrm{HS}^{-}+0.5 \mathrm{O}_{2} \rightarrow \mathrm{S}^{\mathrm{o}}+\mathrm{OH}^{-} \quad \Delta \mathrm{G}=-210.81 \mathrm{~kJ} / \mathrm{mol}
\end{aligned}
$$

Membrane bioreactors (MBR) are known as common type of treatment for low and medium range concentration wastewater. However, only little study has been conducted on MBR treatment of high strength wastewater. MBRs are capable in removing organicand inorganic matter, resisting high organic loading and overcoming settleability problem, however, treating high strength wastewater with the same concept needs more research. ${ }^{5,8}$ The limitation of MBR is membrane fouling, which causes deposition of biosolids cake layer on the membrane surface. ${ }^{1,2,9}$ 


\section{Chemical Engineering Research Bulletin 19(2017) 102-110}

In general, high MLSS improves the performance of MBR since high biomass content tends to increase the biodegradable process. However, the high MLSS concentration enhances membrane fouling due to suspended solid accumulation. The suspended accumulation is closely related to SRT's behavior. It is reported that by changing the SRT, it produces more sludge and increases MLSS concentration. ${ }^{10}$ As highlighted in Mutamim et al. (2013), SRT is performed dependently with HRT in conventional activated sludge to ensure the flocs are well settled in clarifier tank. However, this does not happen in MBR because SRT is an independent variable. SMP and EPS are the parameters that majorly contribute to the fouling problem in MBR. Increased SRT will reduce the production of SMP and EPS. However, SRT that is too high will produce high accumulation of biomass in the reactor, leading to fouling effect. ${ }^{2,11}$ This scenario occurs due to starvation condition created, thereby reducing the production of SMP and EPS. ${ }^{2}{ }^{10}$ Ahmed et al. 2007 stated that the sequence of anoxic/anaerobic MBR at SRT for more than 60 to 100 days have less EPS formation and low bio-fouling occurrences. ${ }^{12}$ Masse et al. (2006) compared between submerged MBR and activated sludge process (ASP) and found that there was no significant difference in sludge production for both operations, but the sludge production in submerged MBR decreased as SRT increased. ${ }^{13}$

U-shaped membrane in bioreactor has the tendency to foul faster than any other type of membrane. Nonetheless, it is usually selected because it is less costly, compact, has low water hold-up and is easy to clean by backwashing. ${ }^{14}$ Hence, this study focuses on the relation between MLSS and SRT on impact of membrane biofouling in treating high strength SSC using aerobic submerged u-shape MBR (ASMBR). Three MLSS scenarios which were $5 \mathrm{~g} \mathrm{~L}^{-1}, 7 \mathrm{~g} \mathrm{~L}^{-1}$ and $9 \mathrm{~g} \mathrm{~L}^{-1}$, consecutively without any sludge discharge, and three SRTs scenarios which were 20, 40 and 80 days consecutively had been studied. TMP morphology had been conducted to investigate both studies. Resistance in series (RIS) was analyzed in MLSS study and SMP and EPS of activated sludge were analyzed in MLSS and SRT studies to assess the fouling morphology.

\section{Materials and Methods}

\section{Operational of u-shaped MBR}

In this study, the laboratory scale of ASMBR was used. Three different SRT scenarios were operated in this study, which were 20, 40 and 80 days consecutively. U-shape hollow fiber membrane made from PES polymer with surface area $0.075 \mathrm{~m}^{2}$ and $0.2 \mu \mathrm{m}$ of pore size was submerged into $4 \mathrm{~L}$ MBR. Dissolved oxygen was maintained above $2 \mathrm{mg} \mathrm{L}^{-1}$. The membrane flux was maintained at $4 \mathrm{LMH}$ by vacuum driven and 5 minutes/1 minute of filter/relax cycle had been applied to prolong the membrane life. Constant flux mode had been applied. Sludge from petrochemical industry was used, which was acclimatized with synthetic wastewater for a month and acclimatization for each MLSS concentrations and SRTs was continued until the effluent quality was stable. New membrane had been applied for of each SRT scenarios. Equation below shows the influent flowrate when applying filter/relax cycle.

$$
Q_{p e r}=\frac{J \cdot A \cdot t_{f i l}}{t_{f i l}+t_{r e l}}
$$

where is the permeate flowrate $\left(\mathrm{L} \mathrm{h}^{-1}\right), \mathrm{J}$ is the membrane flux and maintain at $2 \mathrm{LMH}, \mathrm{A}$ is the membrane area $\left(\mathrm{m}^{2}\right)$, is the filtration time ( $\left.\mathrm{min}\right)$ and is the relaxation time $(\mathrm{min})$.

Each SRT was operated before severe fouling occurred. According to membrane data, performance of TPM of this membrane was below 30kpa before backflush was applied, at maximum pressure of 70 $\mathrm{kPa}$. During the experiment, the fouled membranes were removed by backflush; in which the backflush flux doubled from the filtration flux within duration of 60 seconds for reversible fouling and chemical cleaning by $0.5 \% \mathrm{ppm} \mathrm{NaOCl}$ for 24 hours otherwise irreversible fouling had occurred.

\section{Sulfidic synthetic spent caustic wastewater}

Synthetic SSC was used to avoid fluctuation of chemical content. A synthetic SSC wastewater was prepared by using $0.8 \mathrm{~g} / \mathrm{L}$ of $\mathrm{Na}_{2} \mathrm{~S}$ as sulfide source, $0.5 \mathrm{~g} / \mathrm{L}$ of $\mathrm{NaHCO}_{3}$ as carbon source and $0.7 \mathrm{~g} / \mathrm{L}$ of phenol as non-sulfur source. $10 \mathrm{~mL}$ of nutrient stock was added in wastewater, which consisted of $(\mathrm{g} / \mathrm{L})$; $\mathrm{NH}_{4} \mathrm{Cl}, 0.4 ; \mathrm{KH}_{2} \mathrm{PO}_{4}, 0.2 ; \mathrm{MgSO}_{4} \cdot 6 \mathrm{H}_{2} \mathrm{O}, 0.1$ and 10 $\mathrm{mL} / \mathrm{L}$ trace element and naturalized with $\mathrm{H}_{2} \mathrm{SO}_{4} \cdot{ }^{15}$ Adequate nutrient was added for biomass growth.

\section{Resistance in series}

Critical flux is the turning point between constant and non-constant permeability or reversible and irreversible fouling. Critical flux was determined by using flux step method ${ }^{8}$ for each MLSS. A new membrane was used for each different MLSS concentration, and the critical flux was measured at the beginning of the operation for each MLSS. In flux step method, one step constant was applied for 15 minutes while the corresponding TMP was recorded for every 1 minute. The rate of TMP (dTMP/dt) would be calculated and the critical flux would be identified when $\mathrm{dTMP} / \mathrm{dt} \geq 0.5$. $^{16}$

By using resistance series model as shown in Equation (2), the total filtration resistance could be calculated ${ }^{17}$. The $R_{\text {tot }}$ and $R_{m}$ were obtained by using the 


\section{Chemical Engineering Research Bulletin 19(2017) 102-110}

fundamentals of Darcy's law ${ }^{14}$ that are shown in Equation (3) which correspond with the TMP to the permeate flux $(\mathrm{J})$.

$R_{t o t}=R_{m}+R_{s}$

where $R_{\text {tot }}$ is the total filtration resistance, $R_{m}$ is the clean membrane resistance by deionized water permeability, $R_{s}$ is the sludge filtration that normally includes $R_{c}$ as cake resistance and $R_{f}$ is fouling resistance (pore plugging or blocking).

$R=\Delta P \cdot \mu^{-1} J^{-1}$

where $\mu$ is the viscosity of permeate (Pa.s), $\Delta \mathrm{P}$ is a differential pressure across the membrane $(\mathrm{Pa}), \mathrm{J}$ is flux $\left(\mathrm{m}^{3} / \mathrm{m}^{2} \mathrm{~s}\right)$ and $\mathrm{R}$ is resistance $\left(\mathrm{m}^{-1}\right)$.

\section{Analytical methods}

BOD, COD, sulfide, sulfate, MLSS and MLVSS were measured following Standard Method for Examination of Water and Wastewater. ${ }^{18}$ SMP and EPS of biomass were extracted by using heating extraction method to evaluate their protein and carbohydrate content. Protein was analyzed using Bradford's method, while phenol-sulfuric acid method was used to analyze carbohydrate content. ${ }^{19,20}$

SMP and EPS were analyzed for sludge and cake layer for each SRT. The sludge sample was collected from the reactor after the steady state for each SRT and cake layer of the membrane sample was collected at the end of each SRT studies. These samples were centrifuged at 2700 gforce for 10 minutes to produce supernatant and pellet. Supernatants was then filtered using $0.45 \mu \mathrm{m}$ filter to keep the SMP supernatant free from suspended solid before it could be analyzed. Pellet fraction was resuspended using deionized water and heated in water bath at $80^{\circ} \mathrm{C}$ for 10 minutes to reduce bacteria lysis and release intracellular products. After being heated, the sample was centrifuged at $2700 \mathrm{~g}$ again for another 10 minutes. ${ }^{19}$ Both SMP and EPS supernatants were analyzed for protein and carbohydrate contents.

The morphology of sludge was analyzed by using Trinocular Inverted Biological Microscope PAXIT with object magnification of $\mathrm{x} 40$.Surface, and the cross-sections of membranes were analyzed using SEM Jeol JSM 6390LV.

\section{Results and Discussion}

\section{Characteristic of Synthetic Spent Caustic}

Synthetic spent caustic (SSC) wastewater has stable composition, and in this study, it was used to reduce fluctuation of disturbance by unknown compounds which would present when using real spent caustic. Fluctuation occurred due to the different composition of raw material used and process involved. It was important to control the compounds fluctuation to optimize the comparison result later. Besides that, preliminary study of SSC wastewater was done toward the effect of aeration and membrane in COD removal. COD analysis was done on influence, in reactor without sludge biomass and effluent after the membrane. This resulted in less than $10 \%$ of removal by nature, aeration and membrane with $6.23 \%, 2.9 \%$ and $5.47 \%$ of average COD removal, respectively. This might be due to stable components in SSC such as phenol which were hard to oxidize by natural, aeration and membrane. The COD for SSC wastewater was also stable for four days, which resulted in slight COD removal.

In $\mathrm{pH}$ adjustment process, the sulfuric acid (H2SO4) was chosen because it is more economical beside having less thermal impact and is less corrosive as compared to hydrochloric acid $(\mathrm{HCl}){ }^{4}$ In this study, SSC with $\mathrm{pH} 10 \pm 1$ was adjusted to 7 to 7.5 . This resulted in $7.2 \%$ of COD removal and $8.3 \%$ of phenol removal by $\mathrm{pH}$ adjustment. Sulfate product from sulfide oxidation increased up to $79 \%$. In industry, phenol is usually used as the indicator $\mathrm{pH}$ effect due to its difficulty to be oxidized as compared to sulfide. The $\mathrm{pH}$ adjustment also showed that part of the COD had been removed, which might be from components which were easy to oxidize by acid, for instance sulfide and heat, which could be recovered since the process was an exothermic reaction.

\section{Effluent quality performance}

SSC is known to have high content of sulfide organic and inorganic. The influents of SSC wastewater $\mathrm{BOD}_{5} / \mathrm{COD}$ has a mean of 0.33 , which is categorized as high strength wastewater and contain high sulfide and phenol contaminants. Thus, the SSC was acclimatized by ASMBR, operated for 10 days until steady state was achieved. In the MLSS concentration preliminary test, steady state was achieved with COD removal more than $80 \%$ in MLSS range $5 \mathrm{~g} \mathrm{~L}^{-1}$ with MLVSS/MLSS ratio $0.94 \pm 0.02$. The F/M ratio decreased as MLSS increased, recording 0.78, 0.5 and $0.44 \mathrm{~kg} \mathrm{COD} \mathrm{kg}^{-1}$ MLVSS d $^{-1}$ and more than $95 \%$ of COD removal was recorded, as can be seen in Figure 1. Meanwhile, the SRTs test showed more than $90 \%$ of COD removal for SRTs runs, but according to COD removal performance, SRT 40 and 80 days gave slightly high performance as compared with SRT 20 days, as can be seen in Figure 2. The F/M ratio average recorded $0.81,0.72$ and $0.64 \mathrm{~kg}$ COD kg$~^{-1}$ MLVSS $\mathrm{d}^{-1}$ for SRT 20, 40 and 80 days, respectively, and produced high biomass accumulation as SRTs increased. Thus, at high F/M ratio, no high degrade

CBangladesh Uni. of Engg.\&Tech 104 


\section{Chemical Engineering Research Bulletin 19(2017) 102-110}

substrate was recorded due to high food that was more than the capability of the biomass to degrade and needed longer time to achieve constant organic removal.

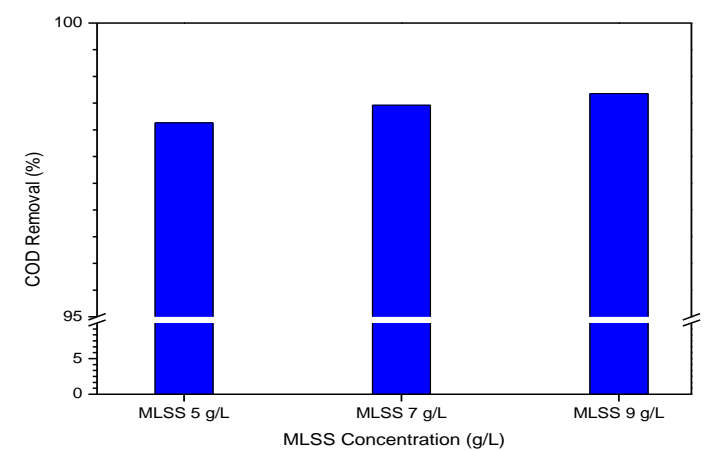

Figure 1: Performance of COD removal on MLSS concentration.

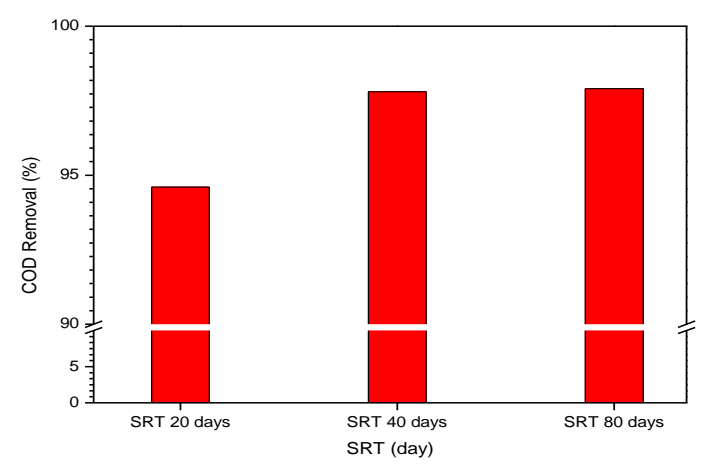

Figure 2: Performance of COD removal on SRT.

\section{TMP rate change and TMP average performance}

In this study, the critical flux was observed for MLSS concentration runs. Appropriate permeate flux (J) operations were identified which should be below the critical flux (Jc) as a flux operation limitation to avoid fouling severity. The strong concepts of critical flux for MF MBR were used as the rate of TMP change greater than $0.5 \mathrm{kPa}$ min- ${ }^{16,21}$ since the TMP change was more than $50 \%$, causing detriment to the membrane. When $\mathrm{J}$ was above Jc, physical or chemical cleaning was required in order to maintain the performance of membrane. ${ }^{10,16}$ Critical flux for $5 \mathrm{gL}-1,7 \mathrm{gL}-1$ and $9 \mathrm{gL}-1$ of MLSS concentration were identified using flux-step method. In flux-step method, 15 minutes for one step constant was applied while corresponding TMP was recorded for every 1 minute. New membrane was used for each different MLSS concentration.

Data from flux step method were used to identify the rate of TMP change (dTMP dt-1) and average TMP (TMPave), as shown in Figure 2 and Figure 3. In this study, the flux with dTMP dt- $1 \geq 0.5 \mathrm{kPa}$ min- 1 was defined as the critical flux. Figure 3 shows that critical flux reading decreased when the MLSS concentration increased. With ability of U-shaped membrane to stand up in vacuum pressure driven at $70 \mathrm{kPa}$, the degree of membrane fouling severity was observed by ascending and descending $\mathrm{TMP}_{\mathrm{ave}}$, as illustrated in Figure 4. At ascending run, the flux increased proportionally with the increase of TMP until the flux leveled off and volume rate of permeate reduced due to high membrane fouling. The membrane fouling severity or detriment was observed during descending run, in which zero flux, $\mathrm{TMP}_{\text {ave }}$ recorded the reading. The degree membrane fouling severity increased when MLSS concentration increased. This was because during filtration, a part of filtrated water retained the colloids and macromolecular matter on the surface of the membrane ${ }^{22}$ and biomass deposit on membrane surface to form thicker biocake layer. Operational flux must be below critical flux, hence the operation flux (J) for next ASMBR runs was under subcritical flux (4 $\mathrm{LMH}$ ), below $\mathrm{J}_{\mathrm{c}}$ with $6 \mathrm{~L} \mathrm{~d}^{-1}$ of SSC influent flowrate to prolong ASMBR operation lifespan.

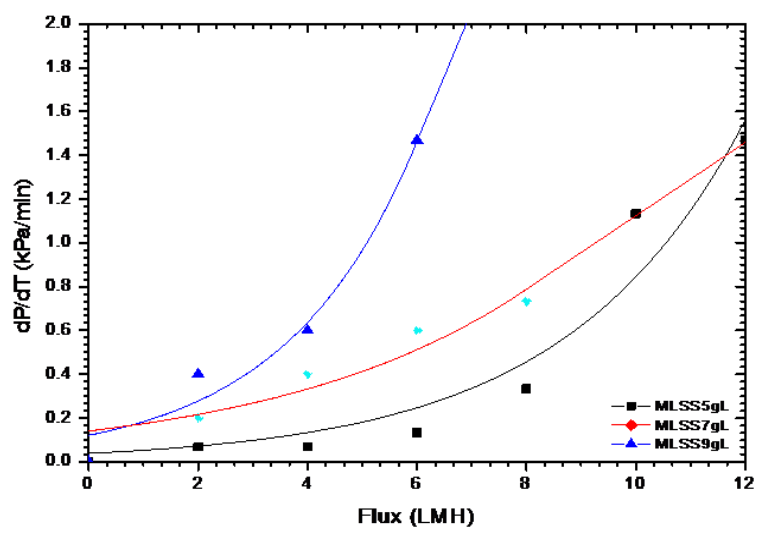

Figure 3: The rate of TMP change (dTMP $\mathrm{dt}^{-1}$ ) for MLSS concentration.

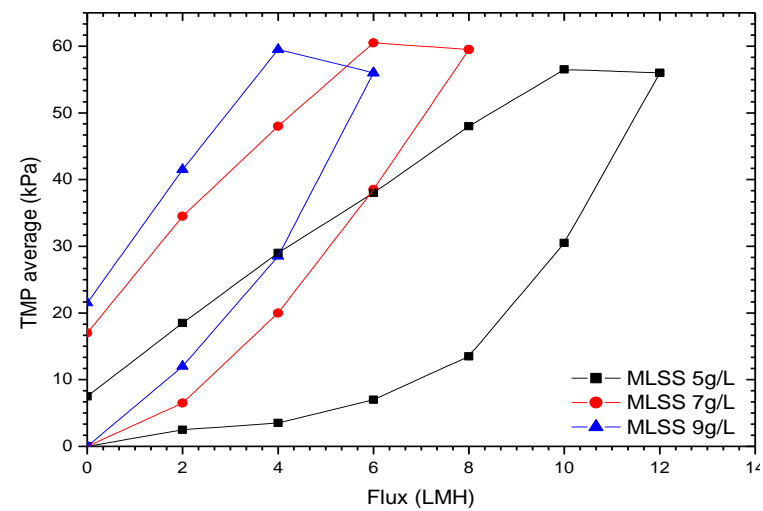

Figure 4: Hysteresis loop for $\mathrm{TMP}_{\text {ave }}$ and flux at each different MLSS concentration. 


\section{Chemical Engineering Research Bulletin 19(2017) 102-110}

\section{RIS and TMP performance}

After critical flux and flux operation were identified in MLSS concentration run, the MLSS concentration performance and SRT optimization performance were proceeded and discussed, including resistance in series (RIS), TMP trend and analytical trend (SMP and EPS and SSC components removal).

Total resistance $\left(\mathrm{R}_{\text {tot }}\right)$ for RIS disaggregated into sludge resistance $\left(R_{s}\right)$ and clean membrane resistance $\left(R_{m}\right)$. $\quad R_{s}$ and $R m$ acted independently, where $R_{s}$ included external fouling (cake layer) and internal fouling. Table 1 shows that the MLSS concentration increased proportionately with the increase of total resistance $\left(R_{\text {tot }}\right)$ without sludge discharge. When the total resistance was high, it led to detrimental flux operation. In this case, the sludge resistance dominated the total resistance, which was due to the cake formation and fouling of the membrane. In $5 \mathrm{gL}^{-1}$ MLSS concentration, $R_{m}$ and $R_{s}$ had slight difference but $R_{s}$ value kept on increasing as the MLSS concentration increased. In this study, Rm significantly affected the $R_{\text {tot }}$ as also reported by $A$. Damayanti et al. (2011) ${ }^{21}$. Likewise, RIS for different SRTs showed that Rtot increased proportionally with increasing SRT, as shown in Table 2. By increasing the SRT, less sludge was discharged while the biomass tended to accumulate in the reactor, and increased the MLSS concentration, biomass products and inert particulate matter and Rtot.

Due to that reason, high biocake layer formed on the surface of the membrane and increased the percentage of $R_{s}$. The biocake layer on membrane surface acted as pseudo-membrane and helped to avoid contaminant passing through the membrane but reduced the efficiency of filterability until cleaning process took place. These were due to adsorption of soluble matter and pore blockage within the membrane, as similarly reported by I. S. Chang et al. (2008) where cake resistance, $R_{c}$ increased when MLSS was increased. ${ }^{23}$ In addition, $\mathrm{Rm}$ might be impeded by the membrane characteristic e.g. membrane porosity or membrane material; and pure water permeability 16 that would lead to detrimental flux operation. Lee et al. (2010) reported that as SRTs increased, the MLVSS also increased, and small MLVSS accumulation had been recorded at low SRT hence the operation became stable after 10 days of operation. ${ }^{24}$ Ahmed et al. (2007) reported that by increasing the SRT, the Rtot could be reduced with EPS formation reduction. ${ }^{12}$

Figure 5 shows the TMP performance of MLSS concentrations and SRTs. In this study, flux was maintained, and the result illustrated the initial TMP for MLSS concentrations while SRTs had slight significant difference. The rapid increase was seen for MLSS concentration rather than SRT due to almost no sludge discharge in MLSS concentration runs. The
TMP start sharp changed on day 4 for MLSS $9 \mathrm{gL}^{-1}$ due to drastic increase of biomass and inert suspended accumulation in the reactor since there was almost no sludge discharge for MLSS concentration runs. Same results were reported by Bottino et al. (2009) and Melin et al. (2006) whereby increasing MLSS concentration hastened membrane fouling. ${ }^{16,25}$ Meanwhile, on SRT 80 days, the TMP rapidly increased as compared to SRT 20 and 40 days due to less sludge discharge that increased the inert compound and biomass accumulated in the reactor. Besides that, solids accumulation in the system tendency clogged the membrane channels and reduced the efficiency of aeration. This record was in contrasts to the findings by Rosenberger et al., (2006) and Ahmed et al., (2007), where low SRT reported high membrane biofouling as compared with long SRT. ${ }^{12,26}$

Table 1: Resistance in series (RIS) in different MLSS concentration without sludge discharge.

\begin{tabular}{|c|c|c|c|c|c|}
\hline $\begin{array}{c}\text { MLSS } \\
\left(\mathrm{mg} \mathrm{L}^{-1}\right)\end{array}$ & $\begin{array}{c}\mathrm{R}_{\text {tot }} \\
\left(10^{12} \mathrm{~m}^{-1}\right)\end{array}$ & $\begin{array}{c}\mathrm{R}_{\mathrm{m}} \\
\left(10^{12} \mathrm{~m}^{-1}\right)\end{array}$ & $\begin{array}{c}\mathrm{R}_{\mathrm{m}} \\
\%\end{array}$ & $\begin{array}{c}\mathrm{R}_{\mathrm{s}} \\
\left(10^{12} \mathrm{~m}^{-1}\right)\end{array}$ & $\begin{array}{c}\mathrm{R}_{\mathrm{s}} \\
\%\end{array}$ \\
\hline 5000 & 1.718 & 0.778 & 45.3 & 0.94 & 54.7 \\
\hline 7000 & 2.65 & 0.778 & 29.4 & 1.872 & 70.6 \\
\hline 9000 & 6.626 & 0.778 & 11.7 & 5.848 & 88.3 \\
\hline
\end{tabular}

Table 2: Resistance in series (RIS) in different SRTs.

\begin{tabular}{|c|c|c|c|c|c|}
\hline $\begin{array}{c}\mathrm{SRT} \\
(\mathrm{day})\end{array}$ & $\begin{array}{c}\mathrm{R}_{\text {tot }} \\
\left(10^{12} \mathrm{~m}^{-1}\right)\end{array}$ & $\begin{array}{c}\mathrm{R}_{\mathrm{m}} \\
\left(10^{12} \mathrm{~m}^{-1}\right)\end{array}$ & $\begin{array}{c}\mathrm{R}_{\mathrm{m}} \\
\%\end{array}$ & $\begin{array}{c}\mathrm{R}_{\mathrm{s}} \\
\left(10^{12} \mathrm{~m}^{-1}\right)\end{array}$ & $\begin{array}{c}\mathrm{R}_{\mathrm{s}} \\
\%\end{array}$ \\
\hline 20 & 1.637 & 0.778 & 47.5 & 0.859 & 52.5 \\
\hline 40 & 1.755 & 0.778 & 44.3 & 0.977 & 55.7 \\
\hline 80 & 5.541 & 0.778 & 14 & 4.763 & 86 \\
\hline
\end{tabular}

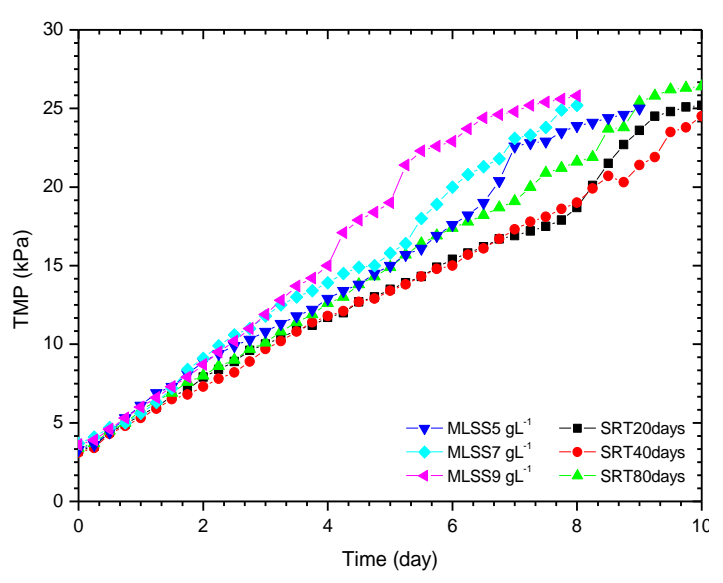

Figure 4: TMP performance for MLSS concentration and SRTs.

\section{SMP and EPS performance}

The performance of MLSS concentrations and SRTs also were observed during the production of microbial product (SMP and EPS). SMP is known as soluble cellular component, which was released during cell lysis and diffused through the cell membrane. SMP also became part of effluents. ${ }^{19}$ EPS was located on or outside the cell surface. In other words, EPS is a medium to connect among cells in microbial 


\section{Chemical Engineering Research Bulletin 19(2017) 102-110}

aggregates. EPS can be transformed into many organic compound such as polysaccharides, amino polysaccharide and protein. ${ }^{27} \mathrm{SMP}$ and EPS in common microbial can be used to produce organic materials that contain electrons and carbon but they are not active cells. ${ }^{28}$ In MLSS concentration runs, SRTs were almost infinity.

MLSS concentration in Figure 5(a) shows average SMP and EPS records. In order to get the best performance of ASMBR in treating in high strength spent caustic, MLVSS concentration must be high to increase degradation process and lead to increase SMP and EPS. As MLSS concentration increased, the F/M ratio decreased. This means that increasing the MLVSS might increase the accumulation of biomass product (SMP and EPS) since there was no sludge discharge. ${ }^{2}$ The reading showed that the average SMP and EPS increased by increasing MLSS concentration, which led to membrane fouling. These results were similar to those reported by Wu et al. (2011), where performance of EPS was high at high MLSS in SRT infinity, which had serious biofouling due to low floc size. ${ }^{29}$ Besides SMP and EPS from biomass, MLSS concentration also consisted of inert suspended solid, inert compounds, dead and old biomass which accumulated in the reactor, since there was no sludge discharge in these runs that contribute to membrane fouling. ${ }^{30}$ As a result, accumulation of SMP and EPS and also inert particulate influence sped up the membrane biofouling due to rapid deposition of bicake layer and biolayer of membrane surface.

Eventhough Figure 5(b) shows that the accumulation of SMP and EPS were low at SRT 80 days and 40 days, the TMP result showed rapid increase at SRT 80 days due to less sludge discharge, and high inert particulate accumulated in the reactor, in contrast with SRT 20 days. The same result was reported by $\mathrm{Ng}$ and Hermanoicz (2005) ${ }^{31}$ The effluent also recorded the existence of SMP and EPS due to soluble SMP and EPS for both MLSS concentrations and SRTs runs. Although the mechanisms of SMP and EPS from biomass synthesis released in bulk solution led to fouling, it still needed to be taken into account. In addition, proteins became more hydrophobic rather than carbohydrates. ${ }^{32}$ Figure 5(a) and (b) shows high accumulation of $\mathrm{SMP}_{\mathrm{c}}$ and $\mathrm{EPS}_{\mathrm{c}}$ in bulk solution that influenced the form of biolayer the most and enhanced the fouling to occur. This result was consistent with the finding by Pan et al. (2010). ${ }^{32}$

The mean of COD effluent was recorded as 0.088 gCOD L $\mathrm{L}^{-1}$ and $0.06 \mathrm{gS} \mathrm{L}^{-1}$ for sulfide effluent in all runs. Meanwhile, sulfate was observed to increase from $0.423 \mathrm{gSO}_{4} \mathrm{~L}^{-1}$ to $0.783 \mathrm{gSO}_{4} \mathrm{~L}^{-1}$. However, the main focus in the operation optimization was on the biofouling reduction since COD removal showed a good performance in all runs (above 90\% COD removal). Overall, the change in MLSS concentration clearly affected the critical flux, RIS and TMP performance with 5 gMLSS $\mathrm{L}^{-1}$ giving good performance as compared to others, with less formation of SMP and EPS. Besides that, high MLSS concentration was also detrimental to the system performance by reducing MLVSS/MLSS ratio and possibility to reduce aeration efficiency, besides increasing the membrane biofouling. Even though high SRT had more advantages in less sludge waste generation but it increased the accumulation of solids. SRT 80 days had high $\mathrm{R}_{\mathrm{s}}$ formation, and TMP increased drastically as compared with SRT 20 and 40 days due to high MLSS accumulation (less sludge discharge). Therefore, SRT 40 days gave a good performance (low SMP and EPS formation, slow rate of TMP increase) in fouling rate reduction. Thus, controlling SRT could control the substrate degradation, excess sludge production and biomass concentration.

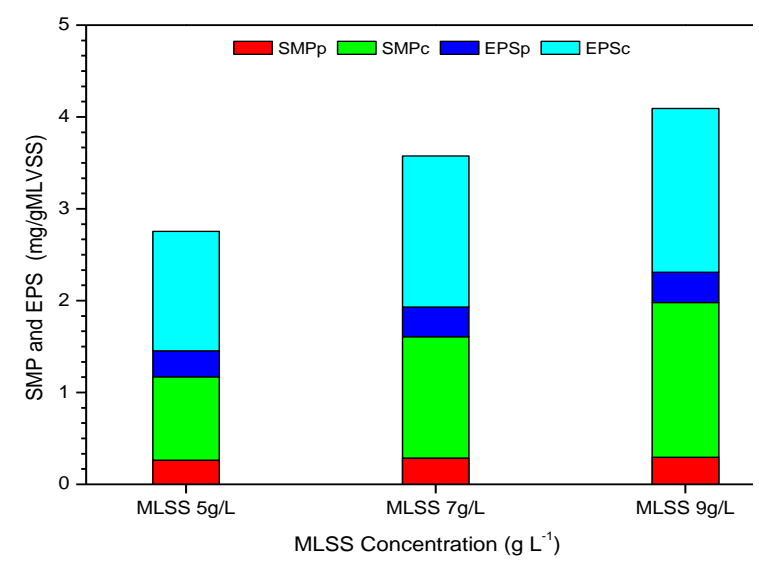

a)

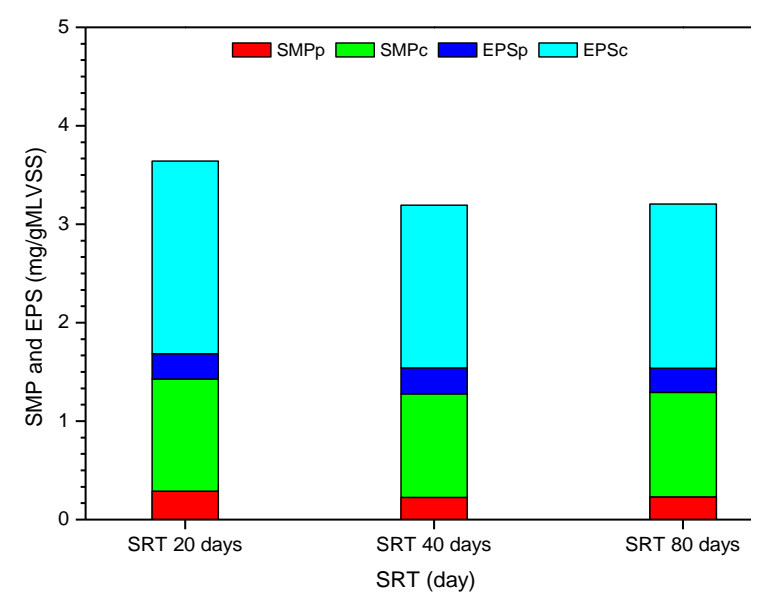

b)

Figure 5: SMP and EPS concentration for (a) MLSS concentrations and (b) SRTs. 


\section{Chemical Engineering Research Bulletin 19(2017) 102-110}

\section{Images from microscope}

Sludge samples were taken and analyzed under microscope at the end of the operation. Figure 6 shows the differences between images of the sludge morphologies. At SRT 20 and 40 days, there are no significant different while at SRT 80 days, the filamentous organisms and free-swimmer organism were retained in the sludge and less foam was reported during the operation due to sludge age. The biomass tended to disperse in bulk solution due to aeration turbulent and less floc strength that led floc easy to unfloc in turbulent condition.
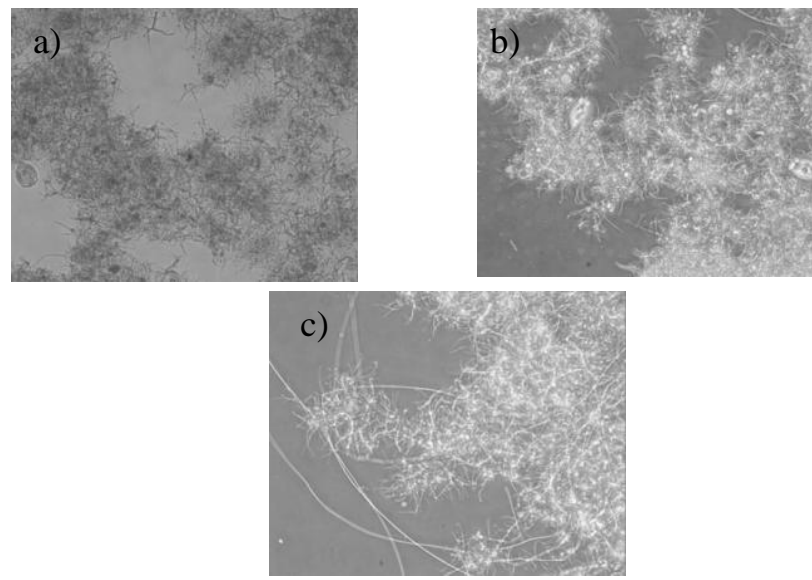

Figure 6: Morphology of activated sludge a) SRT 20 days; b) SRT 40 days; c) SRT 80 days

\section{Conclusion}

As conclusion, ASMBR can be practically be used as it gives positive result in nutrients removal. A RIS model was used to measure the domination of resistances for each component in short term operation for different MLSS concentration in U-shaped. It was observed that high MLSS concentration gave high total resistance. SRT is an important parameter that needs more attention in ASMBR operation. It was found that SMP and EPS affect on MLSS concentration was low as compared to SRT. Without or with low sludge discharge led to sludge age and produced more protein and carbohydrate, which slightly affected the TMP reading. Besides the accumulation of matters such as inert suspended solid, inert compounds, dead and old biomass became a dominant factor of rapid increase of fouling rate. Well-controlled SRT could manage MLSS concentration and reduce the membrane fouling without affecting effluent performance. In addition, uneven air scouring in reactor also caused tendency for biomass to form biocake layer on the membrane surface. The biocake layer became a 'filter' for nutrient remover even though it reduced the flux rate and production rate.

\section{Acknowledgement}

The authors wish to express gratitude to the Research Management Center (RMC) of Universiti Teknologi Malaysia for the financial support under VOT no. 02H27. Credit is also given to Universiti Malaysia Pahang (RDU 150392) for giving generous support to the first author.

\section{References}

1. N.S.A. Mutamim, Z.Z. Noor, M.A.A. Hassan, G. Olsson, "Application of Membrane Bioreactor Technology in Treating High Strength Industrial Wastewater: A Performance Review," Desalination, vol. 305, 1-11,2012a.

2. N.S.A. Mutamim, Z.Z. Noor, M.A.A. Hassan, A. Yuniarto, G. Olsson, "Membrane Bioreactor: Applications and Limitations in Treating High Strength Industrial Wastewater," Chemical Engineering Journal, 225, 109-119, $2013 \mathrm{~b}$.

3. B. Kumfer, C. Felch, C. Maugans, "Wet Air Oxidation Treatment of Spent Caustic in Petroleum Refineries," in: N.P.R.s. Association (Ed.) National Petroleum Refiner's Association Conference, Phoenix, AZ, 2010.

4. F. Berne, J. Cordonnier, "Industrial Water Treatment : Refining," Petrochemicals and Gas Processing Techniques, Gulf Publishing Company, 1995.

5. J. Sipma, A. Svitelskaya, B.v.d. Mark, L.W.H. Pol, G. Lettinga, C.J.N. Buisman, A.J.H. Janssena, "Potentials of Biological Oxidation Processes for the Treatment of Spent Sulfidic Caustics containing Thiols," Water Research, 38, 4331-4340, 2004.

6. M.H. Gerardi, "Wastewater Bacteria," in: M.H. Gerardi (Ed.), John wiley \& Sons, New Jersey, 2006.

7. J. Lohwacharin, A.P. Annachhatre, "Biological Sulfide Oxidation in an Airlift Bioreactor," Bioresource Technology, 10, 2114-2120, 2010.

8. M.d. Graaff, M.F.M. Bijmans, B. Abbas, G.J.W Euverink, G. Muyzer, A.J.H. Janssen, "Biological Treatment of Refinery Spent caustic under Halo-alkaline Condition," Bioresource Technology, 102, 7257-7264, 2011.

9. A. Yuniarto, Z.Z. Noor, Z. Ujang, G. Olsson, A. Aris, T. Hadibarata, "Bio-fouling Reducers for Improving the Performance of an Aerobic Submerged Membrane Bioreactor Treating 


\section{Chemical Engineering Research Bulletin 19(2017) 102-110}

Palm Oil Mill Effluent,” Desalination, 316, 146153, 2013.

10. S. Judd, "Principles and Applications of Membrane Bioreactors in Water and Wastewater Treatment," First ed., Elsevier, U.K., 2006.

11. K. Kimura, T. Naruse, Y. Watanabe, "Changes in Characteristics of Soluble Microbial Products in Membrane Bioreactors Associated with Different Solid Retention Times: Relation to Membrane Fouling," Water Research, 43, 10331039, 2009.

12. Z. Ahmed, J. Cho, B.-R. Lim, K.-G. Song, K.H. Ahn, "Effects of Sludge Retention Time on Membrane fouling and Microbial Community Structure in a Membrane Bioreactor," Membrane Science, 287, 211-218, 2007.

13. A. Masse, M. Sperandio, C. Cabassud, "Comparison of Sludge Characteristics and Performance of a Submerged Membrane Bioreactor and an Activated Sludge Process at High Solids Retention Time," Water Research 40, 2405-2415, 2006.

14. M.C. Malak, "Full-Scale Operation of a Tubular Ultrafiltration System in the Treatment of Oily Waste," in: Civil and Environmental Engineering, West Virginia University, Morgantown, 1999.

15. W. Vishniac, M. Santer, "The Thiobacilli. Bacteriological Reviews,"195-213, 1957.

16. A. Bottino, G. Capannelli, A. Comite, R. Mangano, "Critical Flux in Submerged Membrane Bioreactors for Municipal Wastewater Treatment," Desalination, 245, 748753, 2009.

17. I.S. Chang, S.N. Kim, "Wastewater Treatment using Membrane Filtration-Effect Biosolid Concentration on Cake Resistance,"Process Biochemistry, 40, 1307-1314, 2005.

18. A.P.H.A. APHA, "Standard Method for the Examination of Water and Wastewater," in, American Water Works Association/ Water Environment Federation, Washington DC, USA, 1998.

19. M. Antonelli, K. Bialek, A. Teli, S. Citterio, F. Malpei, "Influence of Thermal Extraction of Extracellular Polymeric Substances on Cell Integrity in Activated Sludge and Membrane Bioreactor Samples," Water Environment Research, 83, 100-106, 2011.

20. S.L. Upstone, "Ultraviolet/Visible Light absorption Spectrophotometry in Clinical Chemictry," in: J.W.S. Ltd (Ed.) Encyclopedia of Analytical Chemistry, Chichester, pp. 16991714, 2000.

21. A. Damayanti, Z. Ujang, M.R. Salim, G. Olsson, "The Effect of Mixed Liquor Suspended Solid (MLSS) on Biofouling in a Hybrid Membrane Bioreactor for the Treatment of High Concentration Organic Wastewater," Water Science and Technology, 1701-1706, 2011.

22. F. Meng, H. Zhang, F. Yang, Y. Li, X. Zhang, "Identification of Activated Sludge Properties Affecting Membrane Fouling in Submerged Membrane Bioreactors," Separation and Purification Technology, 51, 95-103, 2006.

23. C.Y. Chang, j.S. Chang, S. Vigneswaran, J. Kandasamy, "Pharmaceutical Wastewater Treatmnet by Membrane Bioreactor Process - A Case Study in Southern Taiwan," Desalination, 234, 393-401, 2008.

24. D.-Y. Lee, Y.-Y. Li, T. Noike, "Influence of Solids Retention Time on Continuous $\mathrm{H}_{2}$ Production using Membrane Bioreactor," International Journal of Hydrogen Energy, 35, 52-60, 2010.

25. T. Melin, B. Jefferson, D. Bixio, C. Thoeye, W.D. Wilde, J.D. Koning, J.v.d. Graaf, T. Wintgens, "Membrane Bioreactor Technology for Wastewater Treatment and Reuse," Desalination, 187, 271-282, 2006.

26. S. Rosenberger, C. Laabs, B. Lesjean, R. Gnirss, G. Amy, M. Jekel, J.-C. Schrotter, "Impact of Colloidal and Soluble Organic Material on Membrane Performance in Membrane Bioreactors for Municipal Wastewater Treatment," Water Research, 40, 710-720, 2006.

27. Z. Ying, G. Ping, "Effect of Powdered Activated Carbon Dosage on Retarding Membrane Fouling in MBR," Separation and Purification Technology, 2, 154-160, 2006.

28. C.S. Laspidou, B.E. Rittmann, "A Unified Theory for Extracellular Polymeric Substances Soluble Microbial Products, and Active and Inert Biomass," Water Research, 36, 2711-2720, 2002.

29. B. Wu, S. Yi, A.G. Fane, "Microbial Behavior involved in Cake Fouling in Membrane Bioreactors under Different Solids Retention Times," Bioresource Technology, 102, 25112516, 2011.

30. H. Hasar, C. Kinacr, A. Unlu, "Viability of Microbial Mass in a Submerged Membrane Bioreactor," Desalination, 150, 263-268, 2002.

31. H.Y. Ng, S.W. Hermanowicz, "Specific Resistance to Filtration of Biomass from Membrane Bioreactor Reactor and Activated 


\section{Chemical Engineering Research Bulletin 19(2017) 102-110}

Sludge: Effects of Exocellular Polymeric Substances and Dispersed Microorganisms.," Water Environment Research, 77, 187-192, 2005.
32. J.R. Pan, Y. Su, C. Huang, "Characteristics of Soluble Microbial Products in Membrane Bioreactor and Its Effect On Membrane Fouling,” Desalination, 250, 778-780, 2010.

\section{Available online at http://www.banglajol.info/index.php/CERB}

Publisher: Department of Chemical Engineering, Bangladesh University of Engineering and Technology (BUET). Review \&Publication: A submitted original manuscript is taken into review only if the uniqueness is found to be more than $85 \%$ in plag-scanning and selected for publication by the complete acceptance from at least two reviewers out of three. Home Page: http://www.banglajol.info/index.php/CERB . Indexed by Chemical Abstract Service (CAS), CEABA-VtB, Google Scholar, Scopus and DOAJ. 